\title{
Fracture Behavior of Fiber-Resin Composites Containing a Controlled Interlaminar Phase (CIP)
}

\author{
B.Z. Jang \\ Materials Engineering Program, Composite Research Labs \\ 201 Ross Hall, Auburn University, AL 36849 USA
}

CONTENTS

Page

ABSTRACT …

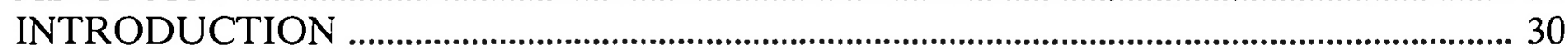

REVIEW OF CLOSELY RELATED LITERATURE ........................................................... 30

A. Interleaving ........................................................................................................................ 30

B. Supplementary Reinforcement ......................................................................................... 31

C. Stitched 3-D Reinforcement .................................................................................... 32

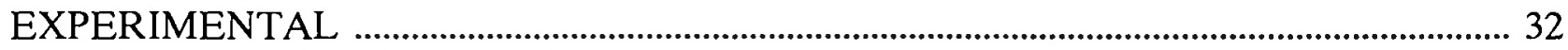

A. Materials and Sample Preparation ................................................................................... 32

B. Mechanical Testing Techniques ...................................................................................... 33

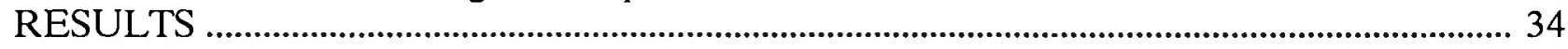

A. Interleaved Composites ............................................................................................. 34

B. Short Fiber Modifications ..................................................................................... 38

C. Stiched 3-D Composites .................................................................................................... 41

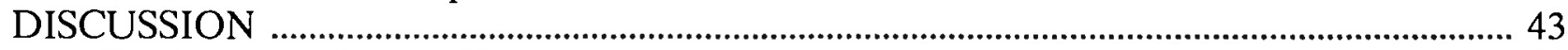

Resistance to Impact Damage ........................................................................................ 43

Mechanisms of Impact Damage ................................................................................. 43

Interlaminar Fracture Toughness ................................................................................. 44

Comparison Among Techniques .................................................................................. 45

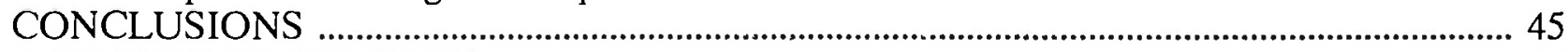

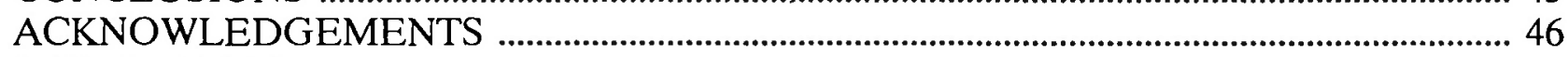

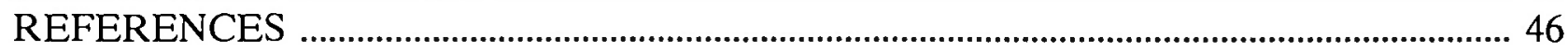




\begin{abstract}
The concept of controlled interlaminar phase (CIP) is suggested as a generic approach to toughening the interlaminar fracture resistance in continuous fiberreinforced polymer composites. In this approach the interlaminar zone in an advanced composite is considered as a discrete phase and the microstructure and properties of this phase are properly designed and controlled. Three examples are given in this report which illustrate how the concept of CIP can be accomplished. These include the techniques of (1) incorporating discrete layers of tough resins (interleaving), (2) adding either particulates, whiskers, or microfibers to the interlaminar zone (supplementary reinforcement), and (3) introducing $z$-directional fibers (stitched 3-D reinforcement). In each case the interlaminar fracture toughness and the damage tolerance of composites were significantly improved. Also discussed in this report are the deformation behavior and fracture mechanisms of composites containing a CIP.
\end{abstract}

\section{INTRODUCTION}

The main advantages of polymer composites over conventional metals in primary structural applications are their superior fatigue resistance and strength- and stiffness-to-weight ratios. However, the primary deficiency of the current generation composites, such as graphite/epoxy $(\mathrm{Gr} / \mathrm{E})$, is their poor damage tolerance. The low in-plane and out-of-plane matrix-dominated mechanical properties often result in intraply matrix cracking and delamination in the composite in response to a low energy impact $/ 1 /$. The initiation and growth of these cracks in composites may lead to severe reliability and safety problems. Stiffness, strength, environmental resistance, and durability may be reduced considerably. Understanding of the basic relationships between these failure mechanisms and material parameters is of great academic interest as well as of significant technical importance.

Conventional toughening approaches that involved dispersing a rubbery phase in the matrix resin have lead to an improvement in damage tolerance, but usually at the sacrifice of hot/wet compressive performance $/ 2 /$. In the present investigation, three closely related approaches were taken to achieve the required balance of these critical properties. The proposed controlled interlaminar phase (CIP) concept considers the interlaminar zone as a discrete phase and seeks to design and control the microstructure and properties of this phase. The concept of CIP can be accomplished by (1) incorporating discrete layers of tough resins (interleaving), (2) adding either particulates, whiskers, or microfibers to the interlaminar zone (supplementary reinforcement), and (3) introducing $z$-directional fibers (stitched 3-D reinforcement). These operations can be best illustrated by referring to the diagrams shown in Fig. 1.

An experimental investigation was undertaken to determine the interlaminar fracture behavior in advanced composites containing controlled interlaminar phase (CIP). This research sought to establish a basic correlation between the interlaminar properties and the microstructure of the added CIP and to determine the macroscopic failure modes and microfailure mechanisms in relation to the CIP parameters and loading conditions.

\section{REVIEW OF CLOSELY RELATED LITERATURE}

\section{A. Interleaving}

To account for the effect of possible impact damage, composite structures are usually designed with overly conservative allowables (e.g., a design strain of 0.004 in./in.) that are far less than those obtained with undamaged laminates. Such a conservative design would considerably reduce structural efficiency $/ 2 \%$. One approach taken to improve the damage tolerance of graphite composites without sacrificing hot/wet properties is to employ a high-strain "interleaf" resin between the plies of graphite-epoxy /2-15/. The conventional wisdom behind this approach is that the matrix resin must provide both stiffness and toughness. A high resin modulus is required because the laminate compressive performance is believed to be directly proportional to the resin modulus $/ 16 /$. Fiber kinking and fiber microbuckling, the predominant compressive failure modes in $\mathrm{Gr} / \mathrm{E}$ laminates, are controlled by the resin modulus 17\%. A composite with a rubbertoughened matrix will possess a reduced modulus. In the interleaf approach the matrix resin within the lamina supports the fibers and provides the hot/wet stiffness. The interleaf resin has a high shear failure strain and 
provides toughness at the ply interfaces to prevent delamination $/ 5,7,8,11,15 /$.

Interleaving has been shown to significantly improve the impact resistance of graphite/epoxy and graphite/ bismaleimide composites $16-8,11 /$, as is manifested by an increase in residual compression strength after impact. The results of interlaminar fracture toughness tests indicate a small increase in $G_{I C}$ and a large increase in $G_{\Pi C C}$ for composites with interleaving. In these studies $12,5-8,11,15$ / the shear failure strain of interlead resin has been identified as a key parameter in the impact damage tolerance improvement. From the energy dissipation perspective the "toughness" may be a better index for determining the best interleaf material. The dependence of the composite interlaminar fracture properties on the interleaf behavior has yet to be identified. The plastic deformation mechanisms and the microfailure processes near the interlaminar zones in relation to the microstructure of the interleaf phase remain to be determined. In a similar study $/ 13 /$ interlaminar adhesive layers have been found to be effective in suppressing edge delamination in the laminates subjected to in-plane tension. The adhesive layers in composite laminates also effectively suppress delamination up to very high impact velocities and help reduce the stress concentration effect $/ 10 /$. These studies serve to demonstrate the advantages of utilizing the interleaving concept to improve composite toughness. However, the material variables that dictate the composite toughness need to be defined and optimized.

\section{B. Supplementary Reinforcement}

Garcia and co-workers /20,21/ have suggested a hybrid composite technique for improving the matrix-dominated
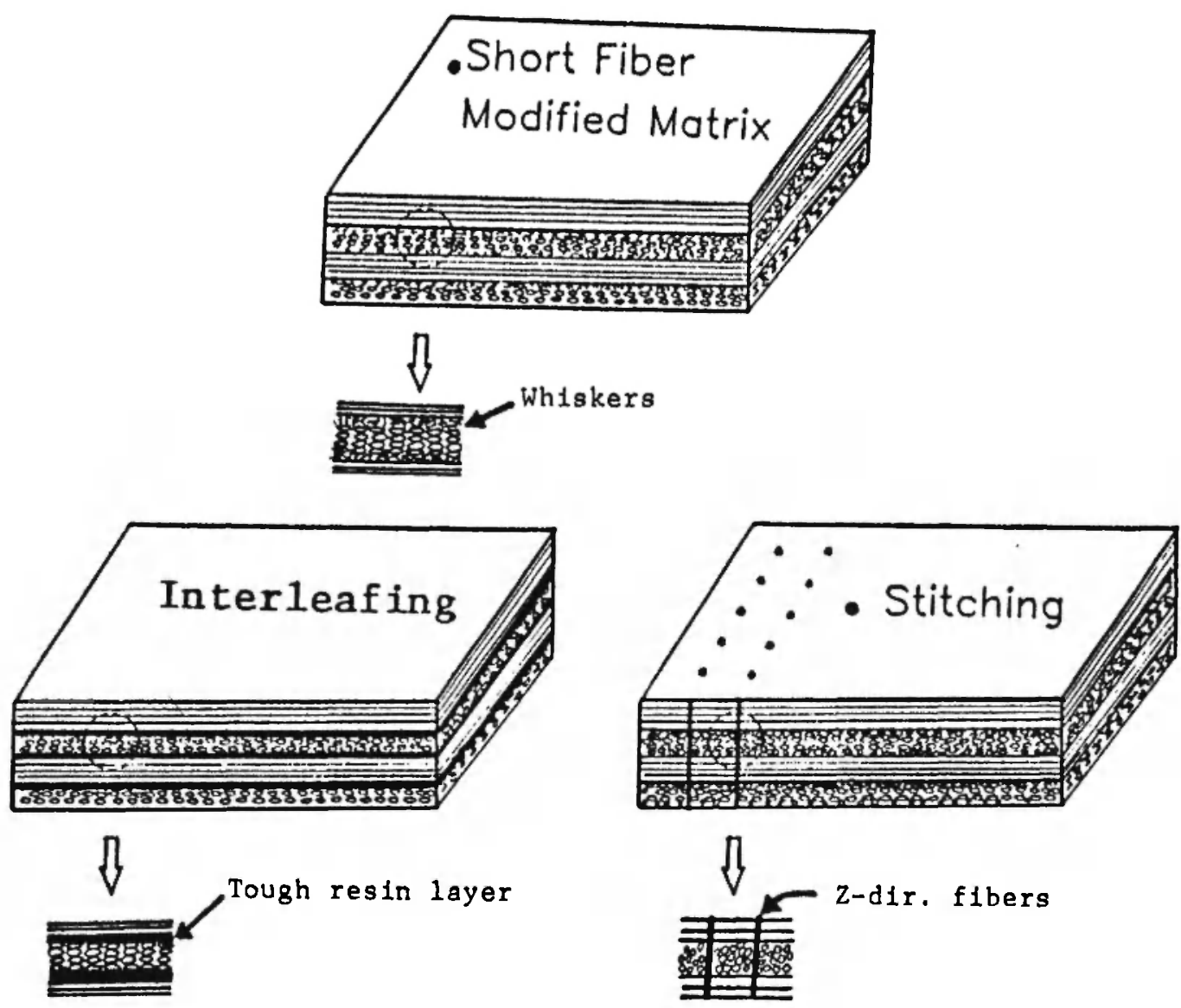

Fig. 1: The three approaches of controlled interlaminar phase (CIP). 
properties of continuous fiber composites. In this technique a supplementary reinforcement, such as particulates, whiskers, or microfibers, is added to the matrix prior to the resin impregnation. This technique does not require the development of new constituent material and is adaptable to the process and equipment currently used to fabricate composites. The transverse tensile strength and strains of the $\mathrm{Gr} / \mathrm{E} / \mathrm{SiC}$ hybrid composites containing $2 \%$ volume of $\mathrm{SiC}$ were significantly increased as a result of incorporating $\mathrm{SiC}$ whiskers $120 \%$. Edge delamination resistance was also improved with $\mathrm{SiC}$ content $>4 \%$ volume. However, fiber damage occurring during the whisker-resin impregnation process often resulted in significant reduction in the in-plane fiber-dominated properties $120 \%$. Jang and co-workers $/ 18,19 /$ have found a significant improvement in impact energy of hybrid composites incorporating either particulates or ceramic whiskers. The relationships between the hybrid composite properties and the microstructure and morphology of the dispersed whiskers need to be established.

\section{Stitched 3-D Reinforcement}

A third way to control the interlaminar properties is to introduce Z-direction (thickness-direction) fibers by the technique of stitching /22-29/. The influence of the stitched Z-direction fibers on the mechanical behavior of an otherwise 2-D composite has been investigated $/ 25$, 27,28/. The 3-D composites have been found to possess a greater damage resistance than 2-D laminates. The $Z$ direction fibers effectively reduce the extent of delamination by increasing the interlaminar shear strength and toughness 127,28 . Stitching not only can help suppress delamination in laminated composites $/ 22 /$ but also can serve as a "joint" in woven composite plates $/ 26 /$. These studies $/ 22-29 /$ have demonstrated the great potential of using stitching in controlling the damage tolerance of composites. Further studies on the processing-structure-property relationships in stitched 3D composites are essential to the proper use of this technique. The Z-direction fibers will modify the interlaminar zones as well as the laminas. The technique of stitching, along with the other two approaches, can be conveniently considered under the same umbrella concept of controlled interlaminar phase (CIP). Other techniques for introducing thickness-direction fibers, such as braiding and weaving, have ben recently reviewed by Jang et al. 27,28 .

\section{EXPERIMENTAL}

\section{A. Materials and Sample Preparation}

The baseline composites were fabricated from either collimated-fiber prepreg tapes (Scotchply SP-319 from $3 \mathrm{M}$ ) or woven fabrics (Hercules). The woven fabrics were impregnated with an epoxy resin prior to press curing. The primary materials investigated were continuous graphite fiber- and Kevlar fiber-reinforced epoxy composites. The raw materials used and their suppliers are listed in Table 1.

The interleaf material was produced in-house to allow for a greater degree of freedom in composition control. The interleaf or adhesive layers must possess functional groups to be co-cured with the matrix resin. A logical choice was to utilize an epoxy resin modified with varying amounts of either liquid reactive rubber (e.g., carboxyl terminated butadiene-nitrile or CTBN) or urethane based prepolymer (e.g., Mobay Desmocap $11 \mathrm{~A}$, a linear aromatic polyurethane) $/ 30 /$. The CTBN and urethane prepolymer were added to generate two separate series of epoxy-based interleaf materials each with a controlled microstructure and properties. The epoxy resin and the modifier were mixed and heated to about $60^{\circ} \mathrm{C}$ until a homogeneous solution was obtained, which was then mixed with. a preheated curing agent. This polymerizing system was then degassed and incorporated in the laminate by coating each prepreg ply with a thin layer of this interleaf resin. These two groups of material should cover a wide spectrum of mechanical properties (modulus, fracture strain, workto-fracture, and fracture toughness for the interleaf phase). The goal of this study was to determine the critical interleaf material factors that would dictate the delamination resistance of the resulting interleaved composites.

In a separate group of composites, short fibers (Kevlar@ aramid and Spectra PE) or whiskers (carbon) were incorporated as supplementary reinforcement in the graphite woven-based composites. The majority of the added whiskers in these composites are expected to stay at the inter-ply boundaries although some will penetrate 
TABLE 1

MATERIALS USED

\begin{tabular}{|c|c|c|}
\hline Materials & Chemical & Supplier \\
\hline Graphite/epoxy prepreg & $\begin{array}{l}\text { Continuous, non-woven graphite } \\
\text { fibers with PR } 319 \text { epoxy }\end{array}$ & 3M Scotchply SP-319 \\
\hline Epoxy resin & & Shell Epon 828 \\
\hline Multifunctional epoxy resin & & Ciba-Geigy Araldite MY721 \\
\hline Hardener: Z & Aromatic polyamine & Shell \\
\hline Hardener: NMA & Anhydride & Anhydrides \& Chem. Inc. \\
\hline Hardener: XUHY 350 & Aromatic diamine hardener & Ciba-Geigy \\
\hline Epoxy 507 & Low curing $T$ epoxy & Ciba-Geigy \\
\hline Hardener 956 & Amine-based & Ciba-Geigy \\
\hline CTBN & $\begin{array}{l}\text { Carboxyl-terminated butadiene- } \\
\text { acrylonitrile copolymer }\end{array}$ & BF Goodrich Hycar CT-RLP \\
\hline Accelerator: BDMA & & Anhydrides \& Chem. Inc. \\
\hline Urethane polymer: Desmocap 11A & $\begin{array}{l}\text { Branched aromatic urethane } \\
\text { polymer with ether groups }\end{array}$ & Mobay Co. \\
\hline Desmocap 12A & $\begin{array}{l}\text { Linear aromatic urethane } \\
\text { polymer with ether groups }\end{array}$ & Mobay Co. \\
\hline Carbon whiskers (VME and VMD) & & Amoco \\
\hline Kevlār»-49 fibers̄s & Aromatic polyamide & DuPont \\
\hline Kevlar® pump & Aromatic polyamide & DuPont \\
\hline Spectra fibers & $\begin{array}{l}\text { Ultrahigh molecular weight } \\
\text { polyethylene }\end{array}$ & Allied Fibers \\
\hline Alumina fibers & $\mathrm{Al}_{2} \mathrm{O}_{3}$ & ICI \\
\hline
\end{tabular}

into the fiber bundles. A proper amount of short fibers or whiskers were dispersed in the epoxy resin prior to resin coating/impregnation of the graphite woven fabrics. Volume fraction of the whiskers can be readily varied between about $1-5 \%$ with respect to the resin.

In the third group z-directional fibers (Kevlar-49, graphite, and E-glass) were introduced through the prepreg tapes or fabric layers (prior to resin impregnation) by hand stitching. The stitch spacing and the number of filaments per stitch were varied as a material parameter.

\section{B. Mechanical Testing Techniques}

Reliable techniques for the damage tolerance assessment of fiber composites are essential to the efforts to develop damage tolerant materials. The most widely used method has been the compression-after-impact test (CAIT) /35-38/. A reliable and more convenient method for characterizing the damage tolerance of polymer composites has been developed by us /40/. This impact fatigue technique involves repeated instrumented impact testing of the same specimen using the same tester (Dynatup I-730 by the General Research Corp). During 
each impact event both load-time and energy-time traces can be recorded along with other significant numerical data. A wide range of incident energies can be applied while the material integrity, as reflected by the stiffness (curve slope), the strength (maximum load), and the energy absorbed, can be monitored as a function of the number of repeated impacts. This technique has been successfully applied to provide toughness measurements on unreinforced polymers $139 /$. One driving force behind comparisons between composite toughness tests is to find a cheaper and faster alternative to the compressive-after-impact (CAI) test. In a practical application the amount of material and labor involved to prepare these $10.2 \times 15.2 \mathrm{~cm}$ coupons for CAI can be prohibitive. In the present investigation the impact fatigue test was used to measure the damage tolerance of composites.

Fracture analysis, testing, and data reduction have been discussed for several interlaminar fracture tests
131/. A few versions of the double cantilever beam (DCB) specimen for Mode I fracture testing have been suggested. The straight-sided specimens developed by Wilkins et al. /34/ were utilized throughout this investigation. The end notched flexure (ENF) test was used to determine the critical strain energy release rate $\mathrm{G}_{\text {IIC }}$ in pure Mode II loading $133,34 /$. The short beam shear test and four-point bending test were conducted for the determination of interlaminar shear properties. The resistance to impact penetration was assessed by the instrumented falling dart test on the unnotched Charpytype and rectangular plate-type specimens.

\section{RESULTS}

\section{A. Interleaved Composites}

Table 2 indicates that the GIIc values of the interleaved composites are significantly higher than those of the

TABLE 2

EXPERIMENTAL RESULTS OF ENF AND DCB TESTS ON THE INTERLEAVED AND CONTROL COMPOSITES

\begin{tabular}{lcc}
\hline \hline Graphite/Epoxy Laminates & GIc $\left(\mathrm{KJ} / \mathrm{M}^{2}\right)$ & $\mathrm{GIIc}\left(\mathrm{KJ} / \mathrm{M}^{2}\right)$ \\
\hline Control composites & 0.197 & 0.68 \\
With interleaf resins: & & 0.96 \\
Epoxy 828 & 0.239 & 1.56 \\
$5 \%$ CTBN toughened epoxy & - & 1.65 \\
$10 \%$ CTBN toughened epoxy & 0.241 & 1.45 \\
$15 \%$ CTBN toughened epoxy & - & 1.55 \\
$20 \%$ CTBN toughened epoxy & 0.293 & - \\
$30 \%$ CTBN toughened epoxy & 0.280 & 0.57 \\
$100 \%$ CTBN, no epoxy & - & 1.34 \\
$10 \%$ PU toughened epoxy & - & 1.38 \\
$15 \%$ PU toughened epoxy & - & 1.24 \\
$20 \%$ PU toughened epoxy & - & 1.17 \\
$30 \%$ PU toughened epoxy & - & 1.06 \\
$40 \%$ PU toughened epoxy & - & \\
\hline
\end{tabular}

*Data are average values of at least nine tests, with a standard deviation of approximately $10 \%$. 
control samples. Although to a lesser extent, the $T_{\text {Ic }}$ values are also improved. When a thin layer of uncured epoxy resin is applied as an interleaf phase between two prepreg layers, a $40 \%$ improvement in $\mathrm{G}_{\mathrm{IIc}}$ is obtained. If the interleaf epoxy resin is modified with $5 \%$ by weight of CTBN, the interleaved composites show a $230 \%$ improvement in the mode II critical strain energy release rate. The degree of improvement is observed to decrease when the CTBN content in the interleaf exceeds $15 \%$. There appears to exist an optimum interleaf parameter where the composites will exhibit the maximum delamination resistance. However, the optimum conditions have yet to be identified.

In a typical impact fatigue test, a load-displacement curve obtained for a specimen in response to the first impact is recorded, which includes the numerical data of the maximum load $\left(\mathrm{Pm}^{\circ}\right)$, the energy absorbed up to maximum load $\left(\mathrm{Em}^{\circ}\right)$, and the elastic modulus or stiffness $\left(\mathbf{S}^{\circ}\right)$. This damaged specimen is then impact loaded for a second time with its load-displacement curve traced and $\mathrm{Pm}^{1}, \mathrm{Em}^{1}$, and $\mathrm{S}^{1}$ calculated. The ratios $\mathrm{Pm}^{1} / \mathrm{Pm}^{\circ}, \mathrm{Em}^{1} / \mathrm{Em}^{\circ}$, and $\mathrm{S}^{1} / \mathrm{S}^{\circ}$ can be taken as a measure for the degree of damage. However, we have found it very informative to overlay many curves together in the same diagram after $\mathrm{n}$ repeated impacts. Figure 2a shows such a diagram for a graphite fiberepoxy laminate (the control sample). As the number of repeated impacts increases, the maximum load tolerated by the material, an indication of the material strength, decreases. Also found decreased is the slope of the loadtime curve, which is proportional to the sample stiffness and modulus, given the same sample geometry. As a result of the stiffness reduction, the maximum deflection is found to increase. In general, the total energy absorption is also reduced as the degree of damage progresses.

Representative curves of impact fatigue tests on interleaved composites are shown in Figure $2 b$ and are further summarized in Figure 3. The composites that contain a $10 \%$ CTBN toughened epoxy resin as the interleaf material can sustain 89 times of repeated impacts and exhibit no significant reduction in the maximum load until just before fracture. However, the control sample only can sustain 5 times of repeated impacts before fracture. This observation demonstrates that an important beneficial effect of interleaving is an improved resistance to transverse cracking and delamination, which are the two major failure modes
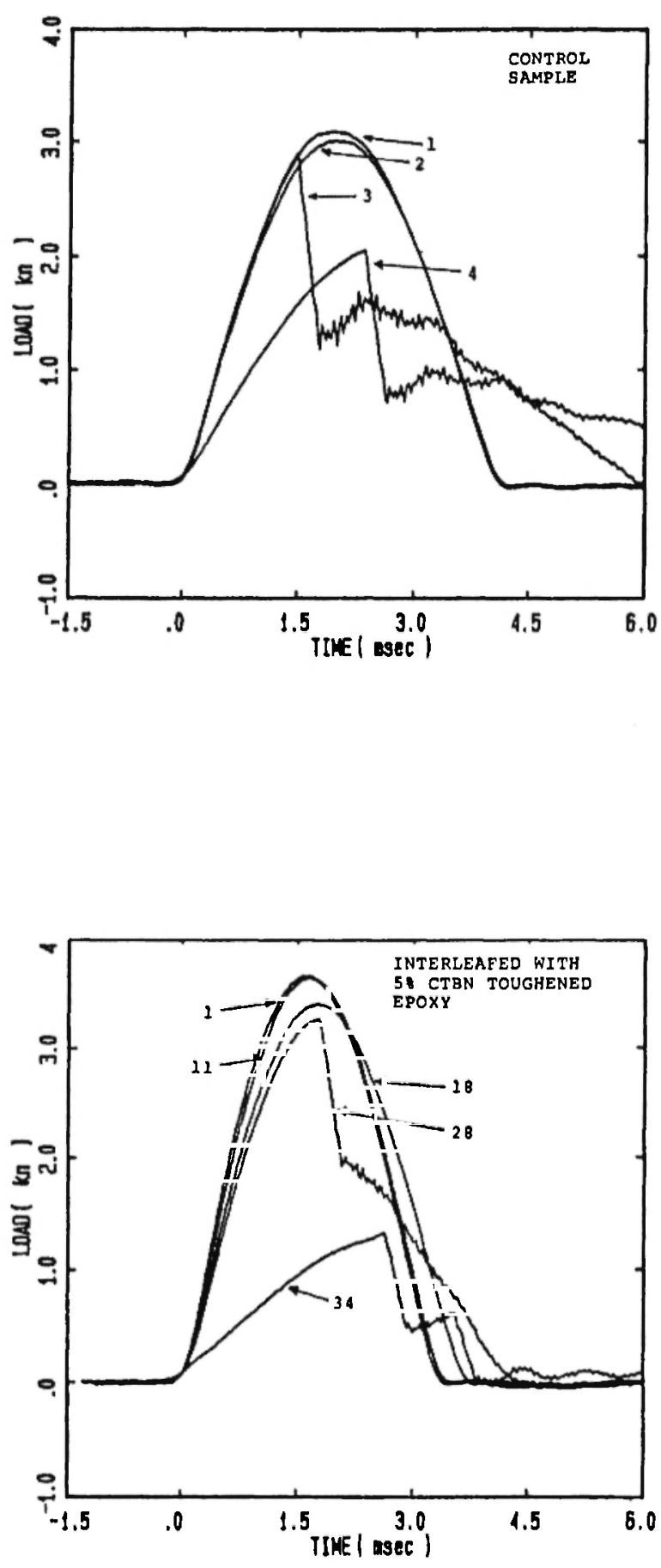

Fig. 2: Overlaid repeated impact traces of fiber-epoxy composites. (a) A control specimen, (b) an interleaved composite. (the number near a curve represents the number of repeated impacts.) /49/ 
leading to the reduced material integrity.

Figure 4A shows selected impact load-time curves of three thin plate samples subjected to impact penetration tests. The initial monotonic increase of the load is due to the front surface indentation by the impactor. The first major break on the load-time curve signals the onset of the failure process. Several humps after the maximum load, Pm, on the load-time curve suggests that there exists a multiple-step failure mode during the impact event. The load is distributed over a large portion of the material and creates more crack surface, reflecting a non-catastrophic failure mode. The incorporation of interleaf layers appears to increase the maximum load slightly. Since the penetration of a projectile through a composite laminate is a fiberdominated phenomenon, the addition of thin interleaf layers was not expected to improve the impact strength to any significant extent. Surprisingly, the total energy absorbed, represented by the area under the load-time curve (Figure 4B), is increased by 3 times in the interleaved specimens as compared to that of the control specimen (Table 3). The more gradual load drop with the interleaved specimens was likely due to the result of plastic deformation occurring in the interleaf layers. As shown in Figure 4, the interleaved specimens also have higher strain-to-failure and higher propagation energy (the energy absorbed after maximum load), Ep. The impact toughness (total absorbed energy) of these interleaved laminates, although controlled by the throughthe-thickness crack, did receive significant contributions from the interlaminar zones.

The ductility index D.I. (Ep/Em) of the interleaved specimen is much higher than that of the control specimen, where Em and Ep are the energy absorbed by the specimen before and after the maximum load, respectively (Table 3 ). This again indicates that a great amount of energy is dissipated during the crack propagation stage of an interleaved composite.

The mechanisms which led to these results became more apparent when the failure surfaces were examined. Scanning electron micrographs of the fracture surface of the baseline laminate were shown in Figure 5A. Very few hackles, a brittle matrix fracture mode, and a poor fiber-matrix interfacial bonding (which eased the

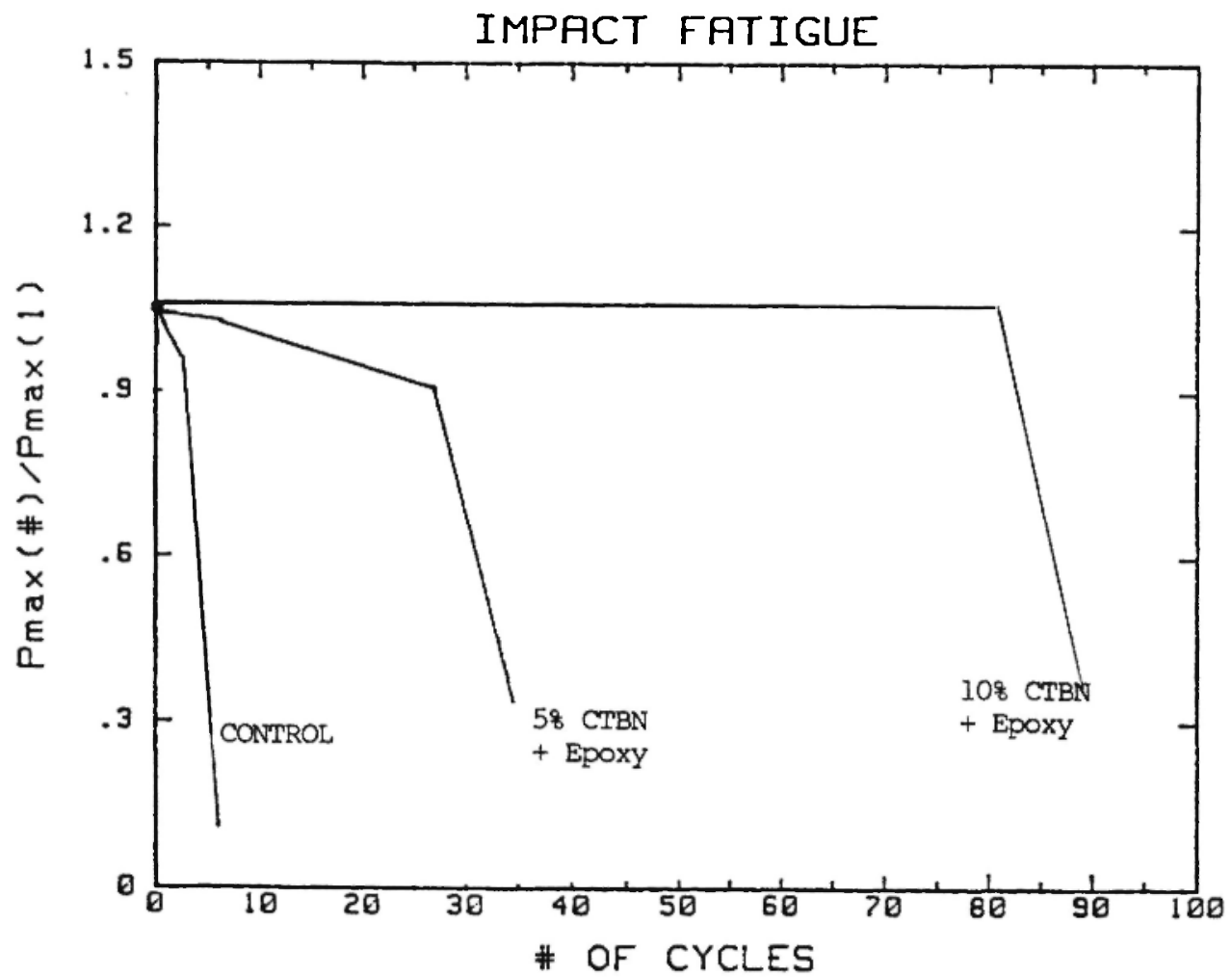

Fig. 3: The ratio of max. load (damaged)/max. load (undamaged) as a function of the umber of repeated impacts. 
delamination) were observed. In contrast, more extensive and an order of magnitude larger hackles were observed in the fracture surface of the $10 \% \mathrm{PU}-828 / \mathrm{Z}$ interleaved composites (Figure 5B). Interfacial debonding between the fiber and the resin was also observed (Figure 5B). Similar fracture features were observed in the CTBN-828/Z interleaved composites during the mode II shear loading (Fig. 5C). In the $100 \%$ CTBN interleaved composite, hackle was completely absent and has been replaced by plastic flow. The mode of delamination propagation in $100 \%$ CTBN interleaved composite was totally different from that in
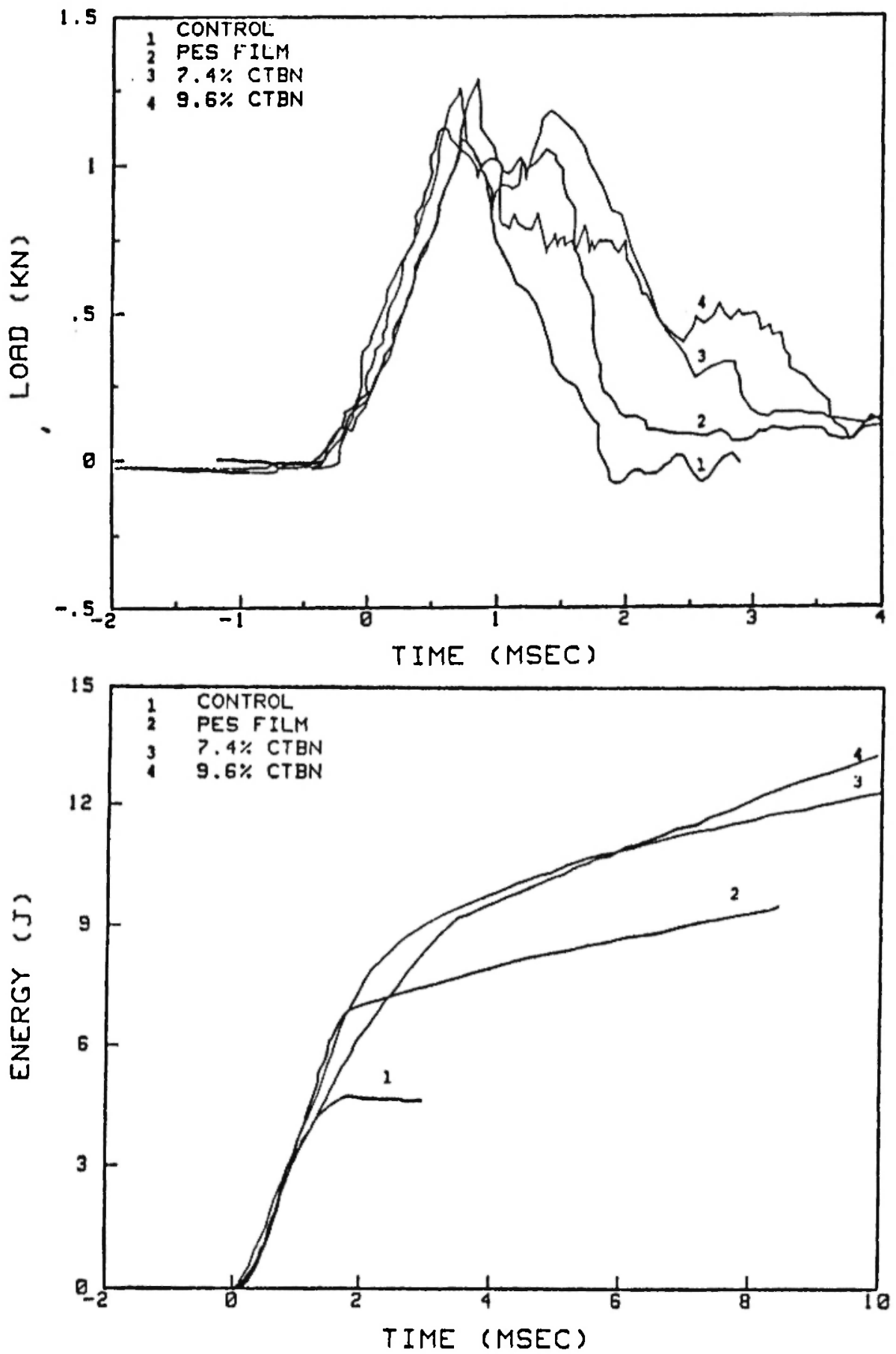

Fig. 4: Results of impact penetration tests conducted on the plate-type samples of control and interleaved composites. (a) Load versus time, (b) Energy versus time curve. 
TABLE 3

THE ENERGY ABSORBED AND DUCTILITY INDEX (D.I.) OF LAMINATES

\begin{tabular}{lcc}
\hline \hline Laminates & $\begin{array}{c}\text { Energy } \\
\text { Absorbed }(\mathrm{J})\end{array}$ & D.I. \\
\hline $\begin{array}{l}\text { Control sample } \\
\text { (un-interleaved) }\end{array}$ & $4.977 \pm 0.330$ & $1.171 \pm 0.296$ \\
$\begin{array}{l}\text { Interleaf resins: } \\
7.5 \% \text { CTBN- }\end{array}$ & $13.846 \pm 2.482$ & $4.172 \pm 0.924$ \\
$828 / \mathrm{Z}$ & & \\
$9.5 \%$ CTBN- & $14.092 \pm 1.101$ & $4.788 \pm 0.692$ \\
$828 / \mathrm{Z}$ & & \\
\hline
\end{tabular}

other interleaved composites in this study. The relatively poor CTBN strength led to cohesive delamination failure (cracking through the CTBN phase) in this laminate, but adhesive delamination failure occurred in other interleaved laminates because of the poorer bonding between the fibers and the interleaf resin.

\section{B. Short Fiber Modifications}

The results of the unnotched Charpy-type impact tests on the short fiber modified composites are summarized in Table 4. The data indicate that the maximum load and the total fracture energy of the composites are significantly improved by modifying the resins with short fibers. When the volume fraction of short fibers increases, the load carrying and energy absorbing capability of composites also increase. The data obtained from the plate-type impact samples (Table 5) also indicate that the contributions to the fracture energy from short fibers are remarkable. Both the maximum load (Pmax) that can be tolerated by and the total energy (Et) absorbed by the composites are improved appreciably. A great amount of strain energy (Ep = Et-Em) is dissipated after Pmax, where the composite is in the crack-propagating stage. The values of Ep are greater in the short fiber-modified composites than in the control composites.

The damage tolerance of a short fiber modified composite is also found to be superior to that of an unmodified version. The impact fatigue results of a control sample (plate-type) and a sample containing $1 \%$
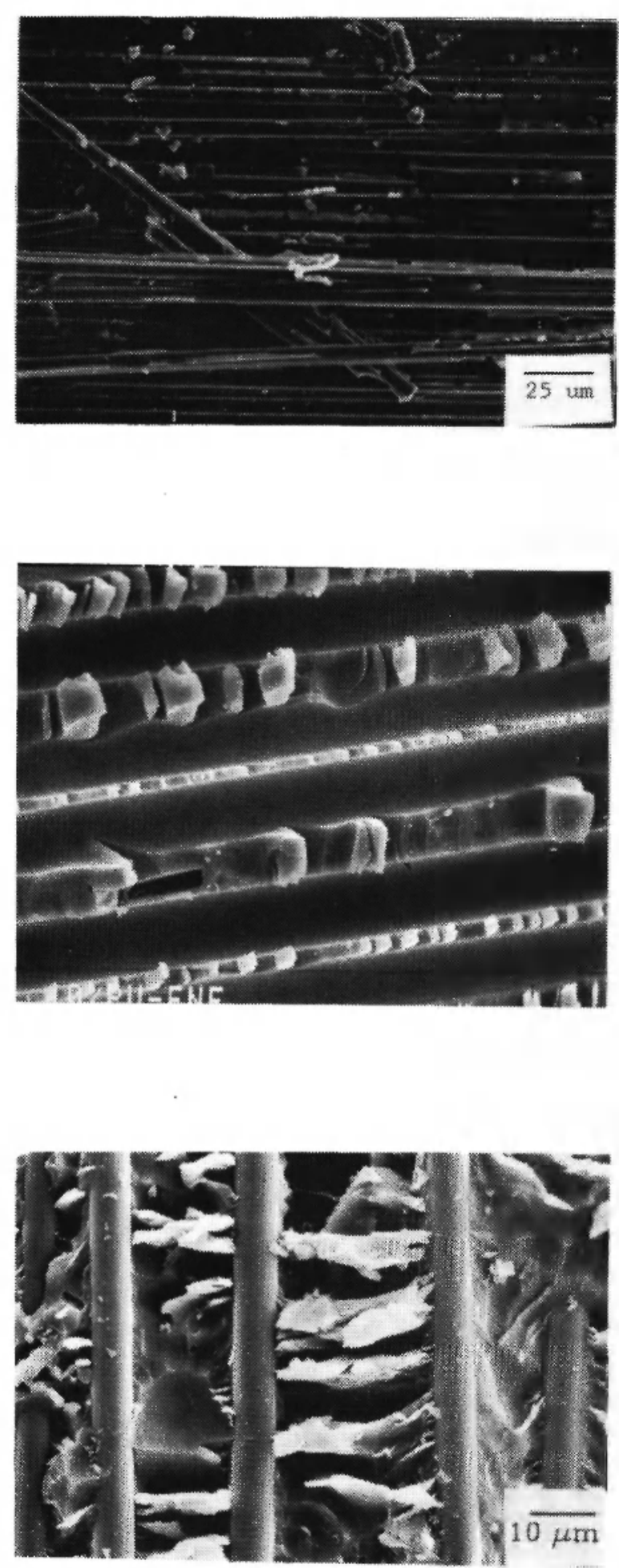

Fig. 5: SEM micrographs of interlaminar fracture surfaces of (a) a control epoxy-carbon composite, (b) a composite interleaved with $10 \% \mathrm{PU}-828 / \mathrm{Z}$, and (c) a composite interleaved with $20 \%$ GTBN-828/ anhydride. 
TABLE 4

IMPACT STRENGTHS OF THE COMPOSITES OBTAINED FROM FLEX IMPACT TEST

\begin{tabular}{|c|c|c|c|c|c|}
\hline Specimen & $P \max (\mathrm{KN})$ & $\mathrm{EM}(\mathrm{J})$ & $\mathrm{Ep}(\mathrm{J})$ & $\mathrm{Et}(\mathrm{J})$ & DI \\
\hline Control & $3.76 \pm 0.29$ & $7.85 \pm 0.72$ & $2.18 \pm 0.20$ & $10.03+0.77$ & 0.277 \\
\hline $1 \%$ Alumina & $4.62 \pm 0.31$ & $8.43 \pm 0.66$ & $2.81 \pm 0.38$ & $11.50 \pm 0.99$ & 0.333 \\
\hline $2.5 \%$ Alumina & $5.86 \pm 0.45$ & $9.93 \pm 0.73$ & $2.69 \pm 0.26$ & $12.62 \pm 0.82$ & 0.270 \\
\hline $1 \% \mathrm{VME}$ & $4.14 \pm 0.24$ & $8.78 \pm 0.36$ & $3.11 \pm 0.89$ & $11.87 \pm 0.80$ & 0.354 \\
\hline $2.5 \% \mathrm{VME}$ & $4.52 \pm 0.32$ & $8.76 \pm 0.86$ & $3.89 \pm 0.27$ & $12.57 \pm 0.05$ & 0.448 \\
\hline $5 \% \mathrm{VME}$ & $5.75 \pm 0.33$ & $9.75 \pm 0.87$ & $3.54 \pm 0.75$ & $13.29 \pm 0.30$ & 0.363 \\
\hline $1 \% \mathrm{VMD}^{*}$ & $4.38 \pm 0.21$ & $8.34 \pm 0.46$ & $4.51 \pm 0.86$ & $12.85 \pm 0.49$ & 0.540 \\
\hline $2.5 \% \mathrm{VMD}$ & $5.78 \pm 0.33$ & $10.85 \pm 0.86$ & $4.54 \pm 0.58$ & $14.59 \pm 0.98$ & 0.451 \\
\hline $5 \% \mathrm{VMD}$ & $5.25 \pm 0.26$ & $10.19 \pm 1.21$ & $4.34 \pm 1.04$ & $14.54 \pm 1.03$ & 0.425 \\
\hline
\end{tabular}

TABLE 5

FALLING-DART IMPACT STRENGTHS OF THE COMPOSITES CONTAINING SUPPLEMENTARY SHORT FIBERS (PLATE-TYPE SPECIMENS) /48/

\begin{tabular}{|c|c|c|c|c|c|}
\hline Specimen & $P \max (K N)$ & $\operatorname{Em}(\mathrm{J})$ & $\operatorname{Ep}(J)$ & $\mathrm{Et}(\mathrm{J})$ & DI \\
\hline Control & $2.48 \pm 0.04$ & $3.49 \pm 0.28$ & $13.18 \pm 1.04$ & $16.67+1.18$ & 3.776 \\
\hline $1 \% \mathrm{VME}$ & $3.26 \pm 0.01$ & $4.92 \pm 0.14$ & $19.66 \pm 2.11$ & $24.57 \pm 2.04$ & 3.995 \\
\hline $2.5 \% \mathrm{VME}$ & $3.41 \pm 0.14$ & $5.07 \pm 0.26$ & $19.96 \pm 3.75$ & $25.04 \pm 3.51$ & 3.936 \\
\hline $5 \% \mathrm{VME}$ & $3.79 \pm 0.09$ & $6.00 \pm 0.26$ & $21.48 \pm 1.15$ & $27.49 \pm 1.00$ & 3.580 \\
\hline $1 \% \mathrm{VMD}$ & $3.06 \pm 0.13$ & $4.84 \pm 1.10$ & $13.40 \pm 1.24$ & $18.20 \pm 0.25$ & 2.780 \\
\hline $2.5 \% \mathrm{VMD}$ & $3.63 \pm 0.16$ & $5.28 \pm 0.28$ & $21.07+1.63$ & $26.35 \pm 1.76$ & 3.990 \\
\hline $5 \% \mathrm{VMD}$ & $3.73 \pm 0.16$ & $5.79 \pm 0.66$ & $23.46+0.84$ & $29.24 \pm 1.36$ & 4.050 \\
\hline $1 \% \mathrm{PE}$ & $2.67 \pm 0.17$ & $6.05 \pm 0.06$ & $15.39+0.18$ & $21.26 \pm 0.40$ & 2.543 \\
\hline $2.5 \% \mathrm{PE}$ & $2.94 \pm 0.10$ & $7.20 \pm 0.26$ & $16.07 \pm 0.58$ & $23.28 \pm 0.56$ & 2.231 \\
\hline $1 \%$ Kevlar & $2.99 \pm 0.12$ & $11.77 \pm 0.91$ & $18.02 \pm 1.65$ & $29.80+1.05$ & 1.531 \\
\hline
\end{tabular}


PE short fibers are shown in Figure 6. While the maximum load of the control sample was reduced from $7 \mathrm{KN}$ to $4 \mathrm{KN}$ at the 15 th impact, the load-carrying capability of the modified composite was reduced to the same extent after 30 repeated impacts. The results from the repeated Charpy-type falling dart tests on the modified composites also demonstrate a considerable improvement in damage tolerance. Short beam shear tests (ASTM D-2344) show that the interlaminar shear strength (ILSS) is also enhanced in the composites containing a small amount of short fibers $/ 18 /$.

The results of both DCB and ENF tests are summarized in Table 6. A distinct improvement in $\mathrm{G}_{\mathrm{Ic}}$ for the specimens containing either 1\% VME, $2.5 \%$ VME or $1 \%$ VMD is observed. But $\mathrm{G}_{\mathrm{Ic}}$ decreases for the specimens containing $5 \%$ of VMD carbon fibers likely because of the presence of voids due to processing difficulty at high fiber loadings. A prominent improvement in $\mathrm{G}_{\mathrm{IIc}}$ for the specimens containing either carbon or Kevlar short fibers is also seen from Table 6.
A SEM study $/ 48 /$ showed that the major fracture mechanisms involved in the DCB test for the control sample were interfacial debonding and matrix cracking with little plastic deformation. Obviously, the delamination resistance of the control sample was mainly dominated by the matrix properties. The same study $148 /$ also showed that in the fracture surfaces of samples containing both $1 \%$ VMD and $2.5 \%$ VME, fracture mechanisms such as interfacial debonding, matrix cracking, short fiber pull-out and breakage, and short fiber-matrix debonding could be easily observed. The mechanical properties of the interlaminar region were apparently improved by these short carbon fibers.

The fracture surfaces of ENF test specimens were also examined by SEM /48/. A clean fracture surface with a few "hackle" structures around the continuous fibers could be seen on the micrograph of the control sample. However, the fracture surface micrographs for the specimen containing 1\% VMD after short beam shear loading indicated the presence of a lot of hackles around

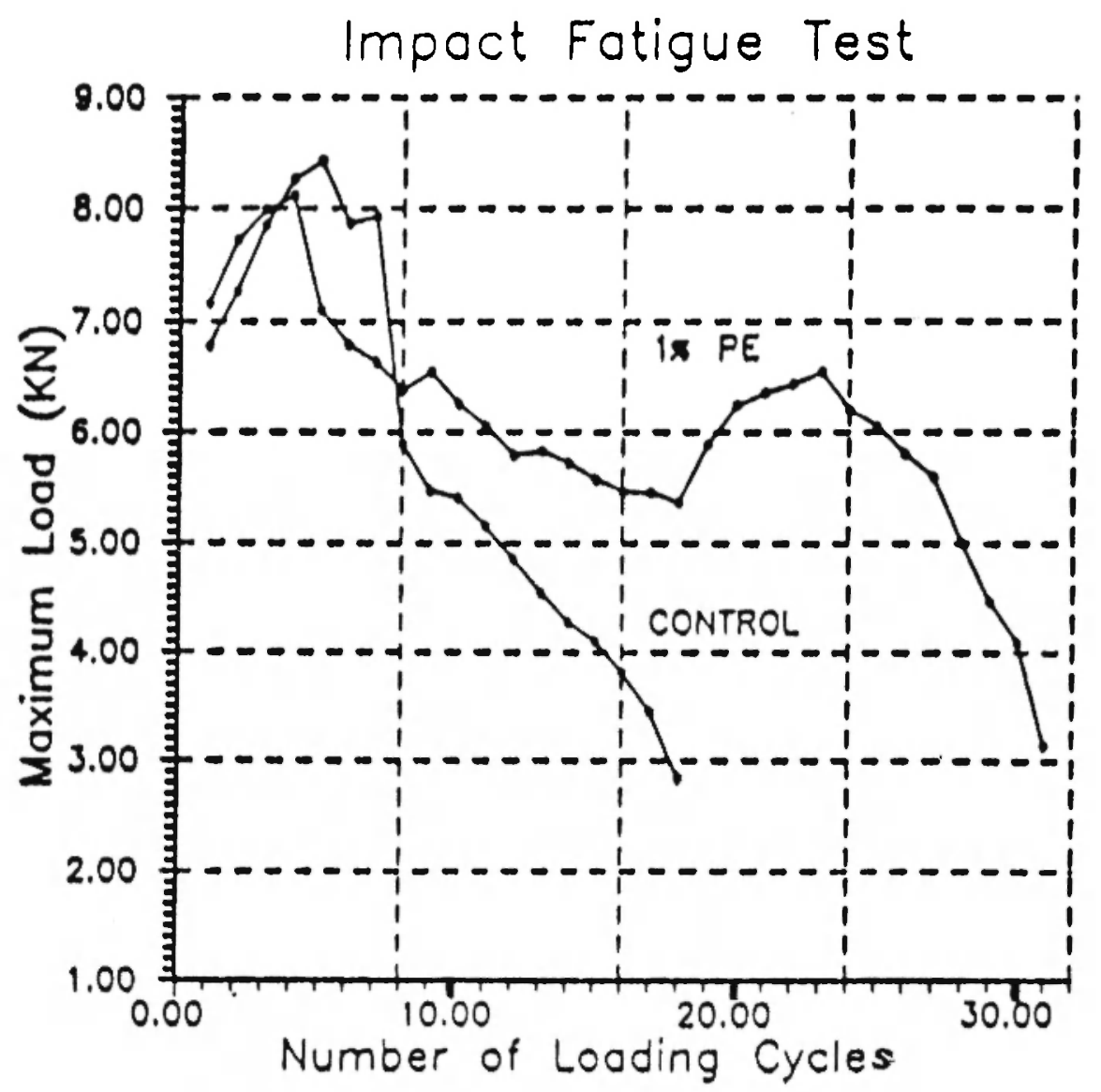

Fig. 6: Results of plate-type impact fatigue tests conducted on an epoxy-carbon fiber control specimen and a composite modified with $1 \%$ supplementary PE fibers. 
TABLE 6

INTERLAMINAR FRACTURE PROPERTIES OF THE COMPOSITES CONTAINING SUPPLEMENTARY SHORT FIBERS /48/

\begin{tabular}{lccc}
\hline \hline Specimen & ILSS $(\mathrm{MPa})$ & $\mathrm{G}_{\mathrm{Ic}}\left(\mathrm{KJ} / \mathrm{M}^{2}\right)$ & $\mathrm{G}_{\mathrm{IIc}}\left(\mathrm{KJ} / \mathrm{M}^{2}\right)$ \\
\hline Control & 46.0 & $1.04 \pm 0.09$ & $1.25 \pm 0.04$ \\
$1 \%$ VME & 48.0 & & $1.48 \pm 0.07$ \\
$2.5 \%$ VME & & $1.37 \pm 0.15$ & $1.66 \pm 0.12$ \\
$5 \%$ VME & 50.0 & $1.25 \pm 0.04$ & $1.60 \pm 0.04$ \\
$1 \%$ VMD & 50.0 & $1.05 \pm 0.04$ & $1.43 \pm 0.05$ \\
$2.5 \%$ VMD & 47.0 & $1.21 \pm 0.17$ & $1.48 \pm 0.06$ \\
$5 \%$ VMD & 43.7 & $1.04 \pm 0.04$ & $1.23 \pm 0.01$ \\
$1 \%$ PE & 41.5 & $0.99 \pm 0.04$ & $0.55 \pm 0.06$ \\
$1 \%$ Kevlar & - & $0.85 \pm 0.01$ & $2.08 \pm 0.15$ \\
\hline
\end{tabular}

the continuous fibers and short fibers. This implies that the matrix resin has been deformed to a great extent under shear loading. In the fracture surfaces of composites containing $2.5 \% \mathrm{VME}$ and $5 \% \mathrm{VME}$ under ENF test, several large hackles around short fibers could be seen. This was likely because the available room for plastic deformation in the short fiber-modified samples was larger than that in the control sample. The larger the area of hackle structure, the more was the strain energy dissipated during the crack propagation. In the composites containing PE short fibers, a clean fracture surface was observed with no "hackle" around the PE fibers. This was attributed to the poor interfacial bonding between PE fibers and the matrix resin.

\section{Stitched 3-D Composites}

The instrumented impact and four-point bending test data obtained from Kevlar and graphite composites have been published elsewhere $127 /$. In response to a highimpact loading, 3D Kevlar-epoxy composites demonstrated a higher level of load-carrying capability and a greater impact energy over their $2 \mathrm{D}$ counterparts. The 2D samples exhibit a step-wise yield drop (a few humps) in the load-displacement curve characteristic of delamination crack propagation and arrest. The 3D composites also showed some delamination, but to a much lesser extent, and did not do so until a very high load was reached. In the case of brittle graphite-epoxy composites, the 3D materials tended to show a brittle impact response. This was believed to be caused by the high tendency for the graphite layers to suffer from fiber damage during stitching. However, 3D graphite composites, just like 3D Kevlar composites, exhibited a lower degree of delamination than their $2 \mathrm{D}$ counterparts. When tested in a lower-rate flexural mode, the 3D versions of both composite types demonstrated an improved flexural strength and an increased amount of energy absorbed $/ 27 /$.

The results of impact fatigue tests on the stitched 3D composites and the corresponding 2D control material are summarized in Table 8. Each of these composites experienced a repeated constant impact load of approximately four joules throughout all 25 impacts, the limit of our patience in this case. This table shows that the 3D composites are able to maintain their strength throughout all 25 impacts, with a $17 \%$ strength reduction in the very worst case. In contrast, the control sample shows a rapidly decreasing maximum load when the number of impacts increases. At the 25 th impact the 
TABLE 7

THE FRACTURE TOUGHNESS OF BULK EPOXY RESINS AND CTBN-TOUGHENED EPOXY RESINS /49/

\begin{tabular}{lccc}
\hline \hline Neat Resin & $\mathrm{K}_{\mathrm{IC}}\left(\mathrm{MPa}^{*} \mathrm{~m}^{1 / 2}\right)$ & $\mathrm{E}(\mathrm{MPa})$ & $\mathrm{G}_{\mathrm{IC}}\left(\mathrm{J} / \mathrm{m}^{2}\right)$ \\
\hline Epon-828/Z & $0.923 \pm 0.089$ & 1240 & $613 \pm 117$ \\
$5 \%$ CTBN-828/Z & $1.55 \pm 0.110$ & 1130 & $1889 \pm 266$ \\
$10 \%$ CTBN-828/Z & $1.53 \pm 0.127$ & 1050 & $1985 \pm 327$ \\
$20 \%$ CTBN-828/Z & $1.31 \pm 0.115$ & 720 & $2124 \pm 370$ \\
& & & $413 \pm 84$ \\
Epon-828/NMA & $0.79 \pm 0.081$ & 1350 & $935 \pm 154$ \\
$10 \%$ CTBN-828/NMA & $1.06 \pm 0.088$ & 1070 & $96 \pm 24$ \\
& & & $133 \pm 30$ \\
\hline
\end{tabular}

1. Tensile modulus from the manufacturer's product data sheet.

2. Tensile modulus from the similar properties of Epon-1079 resin toughened with 10\% CTBN.

TABLE 8

IMPACT FATIGUE RESULTS OF STITCHED 3-D COMPOSITES

\begin{tabular}{lcccr}
\hline \hline & & & & \\
Impact Number & Control 2D & Stitched with Kevlar & With Graphite & With Gle \\
\hline 01 & 3.26 & 3.78 & 3.85 & 4.00 \\
03 & - & 3.55 & 3.61 & 4.20 \\
05 & 2.10 & 3.82 & 3.27 & 3.94 \\
07 & -- & 3.92 & 3.18 & 4.17 \\
09 & -- & 3.90 & 3.35 & 4.09 \\
10 & 2.60 & -- & - \\
11 & -- & 3.87 & -- & 4.00 \\
13 & -- & 3.81 & 3.35 & 3.79 \\
15 & -- & 3.79 & 3.25 & 3.89 \\
19 & -- & 3.92 & 3.26 & 3.74 \\
21 & -- & 3.83 & -- & 3.71 \\
23 & -- & 3.84 & -- & 3.69 \\
25 & 0.35 & 3.77 & -- & 3.64 \\
Max. \% Reduction & & & 3.40 & $9 \%$ \\
\hline
\end{tabular}


control sample has lost $89 \%$ of its original strength. These data clearly demonstrate the advantages that can be gained by applying stitching in improving the damage tolerance of composites.

\section{DISCUSSION}

\section{Resistance to Impact Damage}

Impact damage in composites subjected to a projectile loading is a complex phenomenon. Many damage mechanisms are possible and the extent to which any one damage mechanism predominates depends on the material properties, the structural geometry, and the stressing conditions. In response to the impact of a lowvelocity projectile, a laminate can deform by bending. No damage will occur to the composite if the projectile energy can be accommodated by the elastic strain energy in the material $/ 42 \%$. A critical condition is reached when a local stress exceeds a local strength or when a local strain energy density exceeds a local toughness in the composite.

In a flexural beam with a small span-to-depth ratio, shear failure is more likely to occur in the form of delamination. Dorey $/ 42 /$ suggested that the elastic energy in a beam prior to shear failure would be

$$
U_{\mathrm{S}}=\frac{2}{9} \frac{\tau^{2}}{E} \frac{n t^{3}}{t}
$$

where $\tau$ is the interlaminar shear strength, E the flexural modulus, and $w, 1$ and $t$ the width, span and depth of the beam, respectively. For a beam with a greater spanto-depth ratio, flexural failure is more likely to occur near the top or the bottom surfaces of the beam (near the mid-span). The threshold energy in this case would be $142 /$

$$
U_{\mathrm{f}}=\frac{1}{18} \frac{\sigma^{2}}{E}(w t l)
$$

where $\sigma$ is the flexural strength.

Since our major concern here is to improve the interlaminar fracture properties, we will discuss Eq. (1) in more detail. Keeping sample dimensions equal, one can see that the critical strain energy for crack initiation, $\mathrm{U}_{s}$, is proportional to $\left(\tau^{2} / \mathrm{E}\right)$. Our intention is not to decrease appreciably the magnitude of $E$, which would otherwise compromise the compression strength of composites. Introduction of a thin CIP layer was indeed found to have very little effect on $\mathrm{E}$ of the resulting composite, as was evident from the slope of the loaddisplacement curve in either impact or three-point bending test. A very small decrease, a small increase, and no change in $\mathrm{E}$ were found for the interleaved, the short fiber-added, and the stitched composites, respectively.

For the interleaved composites, the interlaminar shear strength $(\tau)$ as measured by the maximum load in a short-beam flexural impact and in a short beam shear test is only slightly better than that of a control composite. This implies that interleaving does not increase $U_{s}$ to a great extent. The benefits of interleaving therefore do not lie in improving the resistance to crack initiation, but rather in enhancing the crack propagation resistance. This was demonstrated by a remarkable increase in $E_{p}$ and ductility index $E_{p} / E_{m}$ when the composite was interleaved with a small amount of tough resin (e.g., Fig. 4 and Table 3).

Tables 4 and 5 indicate a significant increase in $\mathrm{P}_{\max }$, a measure of $\tau$, when a small amount of supplementary short fibers are incorporated in the laminates. The energy absorbed up to maximum load $\left(E_{m}\right)$, being directly related to $U_{s}$, also exhibits a marked increase. A large increase in $E_{p}$ is also noted. The resistance to both crack initiation and propagation clearly has been enhanced by the approach of supplementary reinforcement.

Four-point bending tests conducted on the stitched 3-D and their 2-D control samples indicate that introducing some fibers in the Z-direction could increase the critical load level, below which no macroscopic crack would be initiated. A remarkable enhancement in the crack propagation resistance is observed from the much more gradual load-drop phenomenon and much greater area under the load-deflection curves in the stitched 3-D composites. Similar results are obtained from the impact penetration tests. However, in the case of stitching through graphite layers, stitching-induced strength of composites. A flexural failure, rather than shear failure, therefore ensued, and Eq. 1 cannot be applied for calculating the resistance to failure initiation.

\section{Mechanisms of Impact Damage}

In an investigation of impact damage in laminated composites, Chang et al. $141 /$ concluded that matrix 
crack was the initial failure mode, which was caused predominantly by the interlaminar shear stresses and inplane tensile stresses. Delamination was initiated by the initial "critical" matrix cracks and delamination growth was dominated by the suddenly increased out-of-plane normal stress as a result of matrix cracking $141 \%$. This study has provided some important guidelines in designing damage tolerant composites. Incorporating Zdirection fibers, either short fibers or continuous fibers, obviously should increase the interlaminar shear strength and, therefore, the resistance to crack initiation. Since some of the short fibers (in the case of supplementary fibers) and all of the long fibers (in the case of stitching) are oriented in the thickness direction ( $Z$ dir.), they should provide dramatic improvement in the ability to endure the out-of-plane normal stresses. The delamination resistance should therefore be enhanced drastically.

Krieger /9/ demonstrated a possible 10 times reduction in the interlaminar shear stress concentration factor when an interleaf resin was added in the laminate. The presence of such a tough resin can also help dissipate the incident energy by undergoing plastic deformation in response to the in-plane tensile stresses and the interlaminar shear stresses.

The composites containing a CIP are more resistant to crack initiation and delamination propagation than the conventional laminates. They are able to absorb more impact energy per unit delamination area created. Given the same incident energy these CIP composites would suffer from a much lesser degree of damage and be more successful in maintaining their structural integrity. The damage tolerance in these composites therefore would be much better, as was demonstrated in the present study.

\section{Interlaminar Fracture Toughness}

Several energy-absorbing mechanisms in a continuous fiber reinforced resin composite during Mode I and Mode II loading have recently been considered by Friedrich et al. 146/. These include: (1) creation of the main-crack fracture surface, (2) development of a damage zone around the crack, and (3) crack bridging by fibers. As pointed out by Friedrich et al. $146 /$, the actual surface area produced during interlaminar cracking may be significantly larger than the projected area $(2 \times$ width $\times$ crack increment) used in the determination of $G_{c}$. The fracture surface is not planar; rather, it contains hackles as can be clearly seen in the SEM micrographs. Both interleaving and short fiber modification have been found to result in the formation of more and larger hackles and hence a much rougher surface. No appreciable variation in hackle pattern has been found with the composites when stitched. Because of the high complexity of the surface roughness encountered in these three CIP cases, no attempt was made to measure the profile length as suggested by Crick et al. $/ 45 /$ and by Friedrich et al. $/ 46 /$.

The volume of the damage zone near the crack tip, where matrix plastic deformation and/or cracking and possibly fiber-matrix interfacial debonding take place, is also an important factor to consider. Bradley and Cohen 144/ assumed that the process zone or damage zone for the composite had the same volume as in the bulk polymer and the toughness of the composite was derived from energy dissipation in the polymer matrix. The composite interlaminar toughness $\left(\mathrm{G}_{\mathrm{co}}\right)$ was suggested $144 /$ to be given approximately by

$$
\mathrm{G}_{\mathrm{co}} \approx \mathrm{C}_{\mathrm{c}, \mathrm{m}} \bullet \mathrm{V}_{\mathrm{m}}
$$

where $G_{c . m}$ is the toughness of the bulk resin and $V_{m}$ is the average volume fraction of matrix over the process zone. To account for the effect of the actual fracture surface area, Eq. (3) was modified /46/ to become

$$
G_{c o} \approx \frac{I_{r}}{I_{p}} V_{m} \cdot G_{c . m}
$$

where $\mathrm{L}_{\mathrm{r}}$ is the profile length $/ 45 /$ and $\mathrm{L}_{\mathrm{p}}$ is the projected crack length. With the introduction of an interleaf phase, which is capable of undergoing a great extent of plastic deformation, the effective values of $L_{r}$, $V_{m}$, and $G_{c . m}$ should increase. The effective magnitude of $G_{c . m}$ at the interlaminar zone clearly should increase when short fibers are added. In short fiber modified continuous fiber composites, the crack tip will interact not only with the misaligned continuous fibers but also with those dispersed short fibers. While the crack tip interacts with the short fibers, more energy will be consumed to break those short fibers. This will also induce fiber-matrix debonding, promote fiber pull-out, and alter the crack path and, therefore, produce more wrinkled fracture surfaces. We have observed previously that interfacial debonding between resin and $Z$ directional fibers as well as breakage and pull-out of 
these fibers can be a major contributor to energy dissipation. We therefore can state that $L_{r}$ and $G_{c . m}$, in a broader sense, can be raised effectively when thickness-direction fibers are introduced in an otherwise conventional 2-D laminate.

Additional energy absorption is possible when crack bridging by fibers occurs, resulting in fiber peeling and fractures $146 \%$. In any attempt to improve the intrinsic fracture toughness of a laminate, these additional contributions to the interlaminar $G_{I C}$ and $G_{I I C}$ can be misleading. In the commonly used interlaminar fracture toughness tests, this "fiber bridging" phenomenon may give a false indication of an otherwise matrix- and interface-dominated $G_{c}$ value. In the composites subjected to a low-velocity impact, transverse cracks and delamination may propagate through a naturally low energy density area, possibly avoiding the misaligned fibers. To discount these fiber bridging contributions to the interlaminar $G_{c}$ values would be a safer design practice as far as damage tolerance of composites is concerned.

\section{Comparison Among Techniques}

Absolute rating of the effectiveness of the proposed three techniques in improving the interlaminar fracture resistance of composites cannot be achieved without ambiguity. The technique of stitching appears to provide the highest interlaminar fracture resistance in terms of CIc, GIIc and ILSS, but often at the expense of in-plane properties because of potential fiber damage incurred. No significant increase is observed with the total impact energy absorbed by the composites when stitched. Stitching through a thick stack of fabric or prepreg layers can be a difficult task in real practice.

Under comparable conditions interleaving seems to be more effective than a supplementary reinforcement approach. This judgement is made on the basis of impact energy and interlaminar fracture toughness values. An improvement in the amount of $46 \%, 32 \%$, and $66 \%$ in Et, GIc, and GIIC, respectively, can be achieved by introducing short fibers in the laminates. The corresponding values for interleaving are $180 \%$, $53 \%$, and $144 \%$, respectively.

\section{CONCLUSIONS}

The following conclusions can be reached from the current research:

1. The impact toughness and penetration resistance of a continuous fiber composite can be effectively improved by modifying the matrix resin with short fibers. In this approach Kevlar short fibers appear to be one of the best candidate supplementary materials. Interleaving is also found to be effective in improving these impact properties, probably because of their high plastic deformation capability. The stitched 3-D laminates generally demonstrate a higher level of load carrying capability and a superior impact resistance over their 2-D counterparts. However, the technique of stitching through prepreg layers could result in a localized inplane fiber damage and a reduction in flexural strength.

2. Short fiber modification of the matrix resin is also effective in improving the interlaminar shear strength (ILSS) of composites. The ILSS values usually increase with the volume fraction of short fibers. But too high a volume fraction of short fibers could create a high void content in composites, resulting in a reduced interlaminar shear strength. Introduction of thicknessdirection fibers via stitching also dramatically raise the ILSS of composites.

3. With an adequate short fiber-matrix interfacial bonding, the approach of short fiber modification appears to be an effective method for improving the delamination resistance and damage tolerance of composites. The interlaminar fracture toughness (both $G_{I c}$ and $G_{I I c}$ ) can be improved by adding a small amount of carbon and Kevlar short fibers to the interlaminar phase. Through-the-thickness stitching has also proved to be effective in suppressing the free-edge delamination in 2-D laminates. The Z-direction fibers tend to inhibit the propagation of delamination and allow for the energy-absorbing mechanisms such as interfacial debonding between Z-direction fibers and matrix and pull-out of $Z$-direction fibers to operate. Interleaving also dramatically enhances the interlaminar fracture toughness of composites.

4. A simple elastic strain energy approach can serve 
as a semi-quantitative framework to assist in the understanding of the resistance to interlaminar crack initiation in composites subjected to a low-velocity impact. Interleaving was found to improve the interlaminar crack propagation resistance, while both the crack initiation and propagation resistance can be enhanced by the techniques of supplementary and Zdirectional reinforcements.

5. The concept of controlled interlaminar phase (CIP) has proven to be a viable approach to improve the damage tolerance of composites. Additional work is needed to understand the correlation between the CIP phase parameters and the composite fracture behavior so that the delamination of a composite can be controlled without sacrificing other properties of composites.

\section{ACKNOWLEDGEMENTS}

The work on stitching was supported by the US Army Research Office, while that on interleaving by the NSF/ Alabama EPSCoR program. The author wishes to thank the general support of these two agencies.

\section{REFERENCES}

1. Joshi, S.P., and Sun, C.T., J. Comp. Mater, 19, 51 (1985).

2. Evans, R.E., and Masters, J.E., "A New Generation of Epoxy Composites for Primary Structural Applications: Materials and Mechanics," in Toughened Composites, ASTM STP 937, ASTM, Philadelphia, 1987, pp. 413-436.

3. Tung, C.M., Liao, T.T., and Leung, C.L., "Cryogenic Tough Materials," 33rd International SAMPE Symposium, 1988, pp. 503-511.

4. Carroll, B., "Improved Toughness of Carbon Fiber Composites via the Use of Thermoplastic Interplies," 33rd International SAMPE Symposium, 1988, pp. 78-90.

5. Krieger, R.B., Jr., "The Relation between Graphite Composite Toughness and Matrix Shear Stress-Strain Properties," 29th International SAMPE Symposium, 1984, pp. 1570-1584.

6. Hirshbuehler, K.R., SAMPE Quarterty, 17, 46 (1985).

7. Dolan, G.L. and Masters, J.E., "Characterization of Carbon/Bismaleimide Interleaved for Improved Resistance to Delamination and Impact," 20th International SAMPE Technical Conference, 1988, pp. 34-45.

Q Masterc IF.. Courter. J.L., and Evans, R.E., "Impact Fracture and Failure Suppression Using Interleaved
Composites," 31st International SAMPE Symposium, 1986, pp. 844-858.

9. Krieger, R.B., Jr., SAMPE J., July/Aug., 30 (1987).

10. Sun, C.T. and Rechak, S., "Effect of Adhesive Layers on Impact Damage in Composite Laminates," in Composite Materials: Testing and Design (Eight Conf.), ASTM STP 972, J.D. Whitcomb, Ed. ASTM, Philadelphia, 1988, pp. 97-123.

11. Masters, J.E., ICCM, 6, 3.96 (1987).

12. Kaw, A.K. and Goree, J.G., ICCM, 6, 3.146 (1987).

13. Chan, W.S., Rogers, C. and Aker, S., "Improvements of Edge Delamination Strength of Composite Materials: Testing and Design (Seventh Conf.), ASTM STP 893, ASTM, Philadelphia, 1986, pp. 266-285.

14. Sun, C.T. and Voit, P.M., Comp. Tech. Rev., [vol.? year?]

15. Hirschbuehler, K.R., "A Comparison of Several Mechanical Tests Used to Evaluate the Toughness of Composites," in Toughened Composites, "ASTM STP 937, ASTM, Philadelphia, 1987, pp. 61-73.

16. Palmer, R.J., "Resin Properties to Improve Impact in Composites," Proceedings of the Fifth DoD/NASA Conf. on Fibrous Composites in Structural Design, NADC81096-60, 1981.

17. Hahn, H.T. and Williams, J.G., "Compression Failure Mechanisms in Unidirectional Composites," NASA Tech. Memo. 85834, 1984.

18. Lin, T.L. and Jang, B.Z., "Mechanical Prop. of Hybrid Composites Containing Both Short and Continuous Fibers," Ann. Techn. Conf. (ANTEC), 35, 1552 (1989).

19. Liau, J.Y., Jang, B.Z., Hwang, L.R., and Wilcox, R.C., Plastic Eng., 44, 33 (Nov. 1988).

20. Garcia, R., Evans, R.E., and Palmer, R.J., "Structural Property Improvements through Hybridized Composites," in Toughened Comp., ASTM STP 937, N.J. Johnston, Ed., ASTM, Philadelphia, 1987, pp. 397-412.

21. Garcia, R., "Methods of. Improving the Matrix Dominated Performance of Composite Structures," NADC-83058-60, July 1983.

22. Mignery, L.A., Tan, T.M., and Sun, CT., "The Use of Stitching to Suppress Delamination in Laminated Composites," in W.S. Johnson (ed.), Delamination and Debonding, ASTM Spec. Techn. Publ. 876, 1985, pp. 371-385.

23. Funk, J.G., Dexter, H.B., and Lubowinski, S.J., "Experimental Evaluation of Stitched Graphite/Epoxy Composites," in NASA Conf. Proc. 2420, 1985, pp. 185205.

24. Du, X., Xue, F., and Gu, Z., "Experimental Study of the Effect of Stitching on Strength of Comnosite I aminate." Int. Symp. on Composite Materials and Structures, 
Beijing, 1986, Technomic, Lancaster, Pa., 1986, pp. 912918.

25. Jang, B.Z. and Chung, W.C., "Structure-Property Relationships in Three Dimensional Reinforced Fibrous Composites," Proc. 2nd Conf. on Advanced Composites: The Latest Developments, Dearborn, MI, 1986, ASM International, Metals Park, OH, 1986, pp. 183-191.

26. Liu, D., Kim, K.G., and Hong, S., "Stitching as Joint in Woven Composite Plates," Advanced Composites III: Expanding the Technology, Proc. of the 3rd Annual Conf. on Adv. Comp., 1987, ASM International, pp. 343347.

27. Chung, W.C., Jang, B.Z., Chung, T.C., Hwang, L.R., and Wilcox, R.C., Materials Science and Eng., A112, 157 (1989).

28. Jang, B.Z., Shih, W.K., and Chung, W.C., J. Reinforced Plastics and Composites, Nov., 538 (1989).

29. Liu, D., "Delamination in Stitched and Non-stitched Composites Plates Subjected to Low-Velocity Impact," Proc. of the Am. Soc. for Composites 2nd Techn. Conf., 1987, Newark, Delaware.

30. Wellner, W., Gruber, H., and Ruttmann, G., "Desmocap: New Solvent-free Epoxy/Polyurethane Combinations," Mobay Product Data, Coating Div, Pittsburgh, Pa., 1988.

31. Carlsson, L.A., and Pipes, R.B., Experimental Characterization of Advanced Composites Materials," Prentice-Hall, Englewood, N.J., 1987.

32. Wilkins, D.J., Eisenmann, J.R., Camin, R.A., Margolis, W.S., and Benson, R.A., "Characterizing Delamination Growth in Graphite-Epoxy," in Damage in Composite Materials, ASTM STP 775, 1980, p. 168.

33. Carlsson, L.A., Gillespie, J.W., Jr., and Pipes, R.B., J. Comp. Mat., 20, [p.?], 1986.

34. Gillespie, J.W., Jr., Carlsson, L.A., and Pepes, R.B., Comp. Sci. \& Techn., 26, [p.?] (1986).

35. Griffin, G.F., "Damage Rolerance of Toughened Resin Graphite Composites," in Toughened Composites," N.J. Johnson, Ed., ASTM STP 437, ASTM, Philadelphia, 1987.

36. Sohi, M.M., Hahn, H.T., and Williams, J.G., "The Effects of Resin Toughness and Modulus on Compressive Failure Modes of Quasi-Isotropic Graphite/Epoxy
Laminates," in Toughened Composites," N.J. Johnson, Ed., ASTM STP 437, ASTM, Philadelphia, 1987.

37. Williams, J.G., "Effects of Impact Damage and Open Holes on the Compressive Strength of Tough Resin/High Strain Fiber Toughness," NASA TM-87756, 1986.

38. Byers, B.A., "Behavior of Damaged Graphite/Epoxy Laminates under Compressive Loading," NASA Contractor Report 159293, 1980.

39. Adams, G.C., "Impact Fatigue of Polymers Using an Instrumented Drop Tower Device," in Toughened Composites," N.J. Johnson, Ed., ASTM STP 937, ASTM, Philadelphia, 1987.

40. Jang, B., Hwang, L.R., and Wilcox, R.C., "Impact Fatigue Testing: A Technique for the Damage Tolerance Assessment of Polymer Composites," SAMPE Symposium, 1989, pp. 480-491.

41. Chang, F.K., Choi, H.Y., and Jeng, S.T., "Characterization of Impact Damage in Laminated Composites," 34th International SAMPE Symp., 1989, pp. 702-713.

42. Dorey, G., "Impact and Crashworthiness of Composite Structures," in Structural Impact and Crashworthiness," Vol. 1, G.A.O. Davies, Ed. Elsevier Appl. Sci. Pub., 1984, pp. 155-191.

43. Elber, W., "Fracture Mechanics in Low-Velocity Impacts on Thin Composite Plates," NASA Technical Paper 2152, 1983.

44. Bradley, W.L., and Cohen, R.N., "Matrix Deformation and Fracture in Graphite Reinforced Epoxies," in Delamination and Debonding of Materials, ASTM STP 876, ASTM, Philadelphia, 1985, p. 389.

45. Crick, R.A., Leach, D.C., Meakin, P.J., and Moore, D.R., J. Materials Sci., 22, 2094 (1987).

46. Friedrich, K., Walter, R., Carlsson, L.A., Smiley, A.J., and Gillespie, J.W., Jr., J. Materials Sci., 24, 3387 (1989).

47. Lauke, B., Schultrich, B., and Barthel, R., Composites Sci. and Technol., 23, 21 (1985).

48. Lin, T.L., and Jang, B.Z., Polymer Composites, 10, 291 (1990).

1. Chen, S.F., and Jang, B.Z., Composites Science and Technology, 41, 77 (1991). 
